\title{
A HOLISTIC APPROACH FOR ASSESSING IMPACT OF EXTREME WEATHER ON CRITICAL INFRASTRUCTURE
}

\author{
M. RÄIKKÖNEN ${ }^{1}$, K. MÄKI $^{1}$, M. MURTONEN ${ }^{1}$, K. FORSSÉN ${ }^{1}$, A. TAGG ${ }^{2}$, \\ P. J. PETIET ${ }^{3}$, A.H. NIEUWENHUIJS ${ }^{3}$ \& M. MCCORD ${ }^{4}$ \\ ${ }^{1}$ VTT Technical Research Centre of Finland Ltd, Finland. \\ ${ }^{2} \mathrm{HR}$ Wallingford Ltd, UK. \\ ${ }^{3} \mathrm{TNO}$, The Netherlands. \\ ${ }^{4}$ Ulster University, Ireland.
}

\begin{abstract}
Urban infrastructures are essential to the health, safety, security and economic well-being of citizens and organisations. Therefore, the managers of critical infrastructures (CI) and infrastructure systems in urban areas need to be constantly aware of and prepared for to any man-made and natural disasters. In this paper, we propose a structured approach to assess extreme weather impacts on CI and discuss how resilience and risk tolerance of critical infrastructure can be enhanced. The approach is aimed at supporting CI owners' and managers' decision-making on a strategic level. It follows a process flow from hazard and $\mathrm{CI}$ identification, vulnerability analysis, potential damage estimation, loss assessment to identification and assessment of measures. The approach incorporates many elements, phases and methods from hazard assessment, vulnerability assessment, risk assessment and cost-benefit analysis (CBA), and combines and incorporates them into one aggregated structure, thus providing a holistic view to risk management and CI protection. The proposed approach is flexible in the sense that it encompasses not only a rigorous quantitative assessment, but also allows for a semi-quantitative or qualitative assessment. In addition, the approach enhances transparency of decision making and contributes to more comprehensive use of available information. The paper is based on research carried out in the INTACT and HARMONISE projects, which are co-funded by the European Union under the 7th Framework Programme.
\end{abstract}

Keywords: cost-benefit analysis, critical infrastructure, extreme weather, measure, resilience, risk, risk assessment, urban infrastructure, urban resilience, vulnerability.

\section{INTRODUCTION}

Infrastructures and infrastructure systems are an essential part of our highly developed society where citizens are increasingly dependent on the availability of infrastructure. These systems such as telecommunications, water supply, sewerage, electricity and transportation are commonly managed in ways involving multiple actors, interests and resources. Within the context of an urban area, large-scale built infrastructure - both planned and existing - is a critical component that is closely intertwined with the integral built environment [1]. This highlights economic and societal relevance of the dependability and resilience of critical infrastructure (CI).

Both natural and man-made disasters can cause severe threats to the $\mathrm{CI}$ and some of these threats are changing over time. One cause of changing threats to $\mathrm{CI}$ is the increased frequency and intensity of extreme weather events (EWE), such as winter storms and drought, and subsequent induced hazards, such as flooding, ice formation and wild fires caused by a changing climate. These present a range of complex challenges to the operational resilience of 
individual CI. In addition, infrastructure systems are typically characterized by a high degree of dependency upon each other, which may cause cascading effects that can multiply the effects of a failure. As not all dependencies are apparent until a disaster occurs and the connection breaks down, the extent of damages may remain unclear until an actual event takes place [2].

Hence, decision makers are pressured to find new ways to cope with the impending disasters and to increase awareness of the overall impacts and risk. Optimal decisions require that decision makers are aware of how their decisions may affect the expected damages [3]. For example, understanding the severity of the impact of the failure of an infrastructure can be used to determine if an infrastructure (or part thereof) is deemed to be critical. Furthermore, careful assessment of potential risk and systematic analysis of dependability of and dependencies between CI can significantly contribute to effective preparedness actions in the event of failure.

It is evident that potential future disasters have to be taken into account when considering protection, mitigation and adaption measures to reflect actual and predicted instances of CI failures. Taking these future disasters and subsequently future risks into account may point out that current measures may not suffice. New or other measures may have to be implemented to protect critical infrastructures (CI) or to mitigate the effects of the inevitable CI failure(s).

\section{OBJECTIVE AND RESEARCH METHODOLOGY}

\subsection{Purpose}

The aim of this paper is to contribute to establishing a systematic approach for performing a risk assessment of critical urban infrastructure and for calculating and comparing benefits and costs of measures. The focus is on natural disasters; especially on EWE and subsequent hazards (e.g. winter storms, flooding, landslides and drought). The underlying research question is: How to assess and treat in a practical way the risk that (future) extreme weather poses to $\mathrm{CI}$ in urban areas? Two further specific objectives of the paper are:

- To propose a practical framework for the risk assessment and treatment that will serve especially strategic decision making.

- To examine how to assess costs and benefits of adaptation, mitigation and protective measures.

\subsection{Case study}

The paper is based on the research carried out in the INTACT (www.intact-project.eu) and HARMONISE (http://harmonise.eu) projects, both co-funded by the European Union under the 7th Framework Programme.

The INTACT project addresses the resilience of critical infrastructures to the challenges faced by extreme weather events. It brings together innovative and cutting edge knowledge and experience in Europe in order to develop and demonstrate best practices in engineering, materials, construction, planning and designing risk mitigating measures as well as crisis response and recovery capabilities. These results will be integrated in the INTACT Wiki, which will provide support to CI operators and CI policy makers to assess and improve the resilience of their infrastructures in the light of changing extreme weather conditions due to climate changes [4].

The HARMONISE project is aiming at developing a comprehensive, multi-faceted, yet mutually reinforcing concept for the enhanced security, resilience and sustainability of urban 
infrastructure and development. HARMONISE will result in resilience enhancement methods for large-scale urban built infrastructure. It will see the development of a concept to improve the security and resilience of this infrastructure, encompassing the design and planning phases of such projects and thereby leading to robust built infrastructure invulnerable to natural and man-made disasters. HARMONISE will improve the design and planning of urban areas, thereby increasing their security and resilience to new threats [1].

One of the baseline cases that has supported and guided our research presented in this paper is a crisis situation due to a heavy winter storm and extreme winter conditions on electricity distribution in South-West Finland in Pirkanmaa (also known as The Tampere Region). The region is a rural area, where a significant share of the electricity lines is located in forests. The weather extremes have become more common during recent years, and there are practical experiences of such events. For example, winter storms in 2001 and in particular in 2010 and 2011 led to the substantial damage to the electricity distribution network [5-7]. The most recent example of snow-induced mass power outages in Pirkanmaa happened in November 2015 when an unexpected amount of unusually wet snow fell on parts of the region, disconnecting electricity supply from tens of thousands of inhabitants.

The most severe aspects of the above-mentioned winter extremes are the power outages. Consequently, after a certain period of power failure, the communication and most ICT systems are typically paralyzed. As the blackout goes on, further problems with fresh water as well as sewage systems materialise. Furthermore, the service actions for such major storm are challenging. Typically, also the road infrastructure is severely damaged, thus service crews suffer difficulties of transportation. Measures proposed to elleviate such problems include heavy underground cabling of power lines that can result in higher costs of electricity transport. Other possible solutions are increased network automation, remote controls and movable reserve power units. Much attention has been drawn to co-operation between utilities and authorities and making an up-to-date situation report open for all parties [5-7].

\subsection{Method}

The main research methodology is constructive research. A content analysis was used to examine and compare the past and present methods of risk and vulnerability assessment, investment appraisal, and Cost-Benefit Analysis (CBA) and to discuss the different aspects of decision-making in this context. The actual approach is based on problem solving and solution building.

\section{APPROACH}

3.1 Risk management to support decision making and to protect critical urban infrastructure

Risk is a topic that receives much attention in the decision-making literature [8]. Complex situations with many risks form the essence of decision-making, with systematic risk assessment being an important stage.

According to the IEC/ISO 31010 standard, a risk assessment encompasses the whole process of risk analysis and evaluation and includes also the comparison of estimated risks against given criteria. Having completed a risk assessment, risk treatment involves selecting and agreeing to one or more relevant options for changing the probability of occurrence, the 
effect of risks, or both, and implementing these options [9]. In principle, ways of managing the risk include adaptation, coping, mitigation and risk transfer. Before the investment decision can be made, alternative measures should be subject to an economic evaluation, i.e. CBA [3]. The primary purpose behind the measure assessment is to determine the long-term implications of decisions. Furthermore, an important aspect is to assess an optimal level for the risk mitigation investment [10].

Another risk management framework that is of interest for INTACT and HARMONISE projects is introduced by the International Risk Governance Council (IRGC). IRGC's framework is an approach to help understand, analyse and manage risk issues for which there are deficits in risk governance structures and processes. The framework comprises five linked phases $[11,12]$ :

- pre-assessment,

- appraisal,

- characterisation and evaluation,

- management and

- communication.

In all, the risk assessment and treatment process introduced in the IEC/ISO standard and the risk management framework developed by the IRGC enhance understanding of the EWE and its impacts on CI. They also help to ensure that uncertainties and risks are adequately considered in a structured and systematic way, thereby allowing them to be incorporated into the planning and decision making. Both processes provide useful information and support the development of the framework described briefly in the next section.

\subsection{Proposed framework}

The proposed framework is a structured approach to assess the EWE impacts on CI (focusing on the ex post performance) and the resilience and vulnerability of CI in urban areas as well as deriving and testing alternative measures and their costs and benefits (focusing on the on ex ante planning). The stages of the proposed framework as considered in the INTACT project and in the case study are presented in Fig. 1.

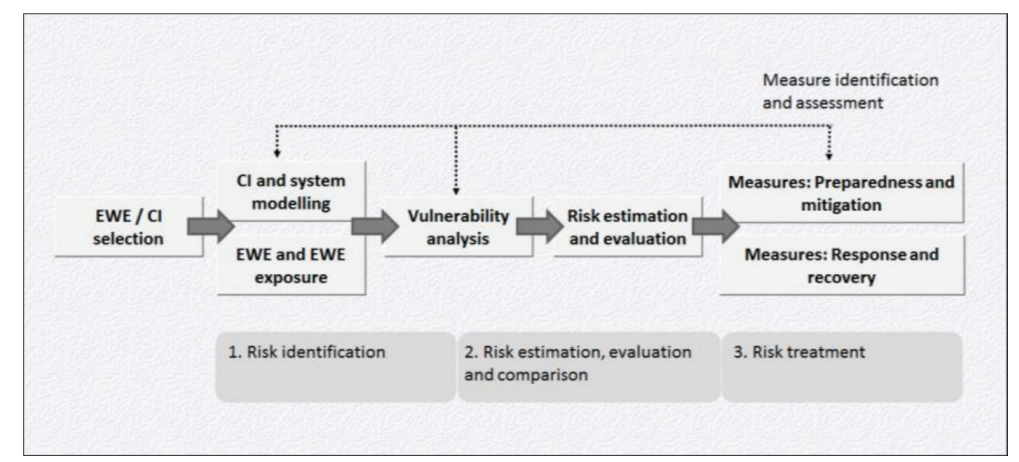

Figure 1: The proposed framework. 
The framework described a process flow from hazard and CI identification, vulnerability analysis, potential damage estimation, loss assessment to identification and assessment of measures (the arrows in Fig. 1). The effect of prevention measures on the physical and logical structure of CI and on the CI vulnerability is illustrated in Fig. 1 with the dashed lines. The process incorporates many elements and phases and supports the use of a variety of methods and tools that can be classified as hazard assessment, vulnerability assessment, risk assessment and CBA. As the process is not always linear and not all steps are conducted sequentially, the tools and methods integrated in each step can of course also be used separately. Additionally, some tools and methods may cover several steps.

The process is flexible in the sense of allowing a user to enter and exit the process at any point. The formal process is accompanied by framing conditions which determine, to a large extent, how the described process steps are followed in a decision situation. This indicates that different decision rules may also be employed in each step. The level of detail and type (qualitative, quantitative, semi-quantitative) in the assessment needs to be consistent with the level of the decision (local, national, EU-level).

\subsubsection{EWE and CI selection}

The first step in EWE in CI selection is to select the CI and EWE to be assessed. The starting point for the development of the framework was that the impacts of one specific EWE-CI combination are assessed at a time. Later, the method can be extended to several simultaneous EWE-CI combinations. The categorisation of EWE and CI used in the INTACT project is presented in Table 1.

\subsubsection{CI and system modelling}

The second step is the determination of core functions and processes of $\mathrm{CI}$ to get a common understanding on CI. Among the basic concepts in the systems-engineering approach are the model of a system and the model of a system life cycle. Such models are presented in, among other places, SE Handbook [14], ISO IEC 15288 [15] and ISO IEC 26702 [16, 17]. These two models can be used to describe CI's hierarchical architecture, related processes, and how various stakeholders are related to various phases in the life cycle [17].

It should be taken into account that the technical information on CI core functions and processes is specific for each CI and system. Therefore, this process step should be conducted

Table 1: The EWE-CI categorisation [13].

\begin{tabular}{ll}
\hline Extreme weather events & Critical infrastructure \\
\hline Heavy rain / flooding & Energy/Power \\
Strong winds / storm & IT/Communications \\
Severe cold & Transportation \\
Snow / ice & Banking \& Finance \\
Severe heat / heat wave & Government Services \\
Drought & Emergency Services \\
Other & Water Supply \\
& Water Management \\
& Food Security \\
& Other \\
\hline
\end{tabular}


in close co-operation with experts, who have the knowledge of the CI and the data access. However, from the decision-making point of view, the data need to be only sufficiently accurate - it does not need to be perfect.

\subsubsection{Risk identification: EWE and EWE exposure}

In this phase of the process, possible EWE situations are identified and described in a more detailed way (e.g. their nature, intensity and duration). Regarding EWE exposure, two concepts are to be dealt with: hazard, which refers to a dangerous phenomenon, substance, human activity or condition (like EWE or a combination thereof), and exposure, which refers to people, systems, or other elements in hazard zones that are thereby subject to potential losses [18]. For some extreme weather types it is possible to combine hazard and hazard exposure into one model. For example, hydrodynamic models can be regarded as hazard and hazard exposure models for floods and inundations. The hazard and hazard exposure models can be deterministic or probabilistic.

\subsubsection{Risk identification: vulnerability analysis}

This step focuses on analysing the physical vulnerability of CI. A comprehensive vulnerability analysis requires not only the consideration of a large number of spatially distributed, interacting elements with nonlinear behaviour and feedback loops, but also a broad spectrum of hazards and threats including failures [19]. In addition to the CI and system modelling [17], the analysis comprises quantification of vulnerability indicators and identification of important elements and application to system improvements that can be either technical or organizational [19].

The two main outputs of a vulnerability analysis of CIs are the quantification of system vulnerability indicators and the identification of critical elements. In all, it can be concluded that conducting a vulnerability analysis is typically a very CI- and EWE-specific task.

\subsubsection{Risk estimation and evaluation}

This step addresses the risk estimation and evaluation focusing on impact and loss assessment. It guides the decision maker with different types of models and examples on how the impact assessment can be concluded. Basically, there are three different types of risk calculations: qualitative, semi-quantitative and quantitative [9]. There are many ways of assessing impacts and various methods have been developed for different purposes. Some methods focus on general mapping and enhancing understanding of the potential consequences and impacts, whereas others involve very detailed analysis in the form of indexing and strict quantitative modelling. A mixture of approaches is used in some cases.

A key aspect in the evaluation phase is the setting of appropriate thresholds for an acceptable risk. For example, an economic framework can be employed to present the EWE impacts as the calculation of economic losses caused by damages is considered as an important part of an impact analysis $[20,21]$. The EWE can cause direct damages involving a complete or partial destruction of CIs in both the public and private sectors. Indirect impacts are flows of impacts that occur over time after the EWE or outside the original location of the EWE. Typically, the indirect impacts are more difficult to express and evaluate in monetary terms than the direct impacts. Indirect tangible costs may include financial elements, such as loss of opportunity through disruption of public services. Business continuity is also a significant component of indirect costs [20,21]. 


\subsubsection{Identification and assessment of measures}

This step addresses the identification of options to manage risk and to assess the costs and benefits of such options. Economic evaluations involve the identification, measurement and valuation, and then comparison of costs (and benefits) of two or more alternatives. In economic evaluations, the costs and consequences of alternative measures (or investments, or scenarios) are compared to examine the best use of the scarce resources [22]. Using any resource for the risk mitigation means the opportunity to use that resource for something else is lost. Therefore, cost-effectiveness (or "value" for money spent) is of central concern. In general, economics helps to choose wisely from a range of alternatives and implement efficient resource, and it preferred to be as wide as possible [21]. However, in some cases, decision makers may wish to know the answers to narrower questions, for example, restricting the perspective to a specific area and on the dependability of the electricity networks.

In the HARMONISE-project, an economic evaluation method and related software tool, RESEC, were developed to support the assessment of economic impacts arising from natural and man-made disasters in urban areas and the decision making on protective, mitigation and adaptation measures with the aim to enhance the security and resilience. RESEC can be considered as a decision-support approach to be applied in the investment planning phase (Table 2). It supports the decision makers to make more transparent, systematic and reliable decisions as it creates a common understanding of the decision alternatives and their possible consequences before the decision takes place [23]. In the next steps of the INTACT project, the CBA on the most promising measures - both in current climate situation and in future will be carried out. RESEC can also guide and support the CBA in the INTACT project.

The RESEC evaluation procedure consists of several steps which are presented in Fig. 2. Each step can be more or less analytical in depth, depending on how detailed data are available and how accurate results are required in current decision-making phase. The procedure might need to be conducted several times before the final decision takes place. For example, in the beginning several measures might be analysed by rough and easily found data and after that a few options can be selected for the detailed analysis [23].

\subsubsection{Results of the proposed framework}

As a result of applying the proposed approach (the framework for risk assessment and treatment, the method for assessment of costs and benefits of measures), different kinds of indicators can be presented for valuation. In order to make a complete assessment, it is necessary to take into account all of the items and elements (hazard, vulnerability etc.). This means that typically the combination of the methods and tools should be used. For example,

Table 2: The purpose of RESEC.

\begin{tabular}{l} 
RESEC procedure and related software tool \\
\hline $\begin{array}{l}\text { What - To support investment decisions on protective, mitigation and adaptation } \\
\text { measures }\end{array}$ \\
Why - To make different aspects affecting decisions visible \\
To determine and compare economic impacts of measure options \\
Who - CI owners, managers and local authorities responsible for large scale urban \\
infrastructure \\
When - Especially in the early phases of the investment decision-making
\end{tabular}




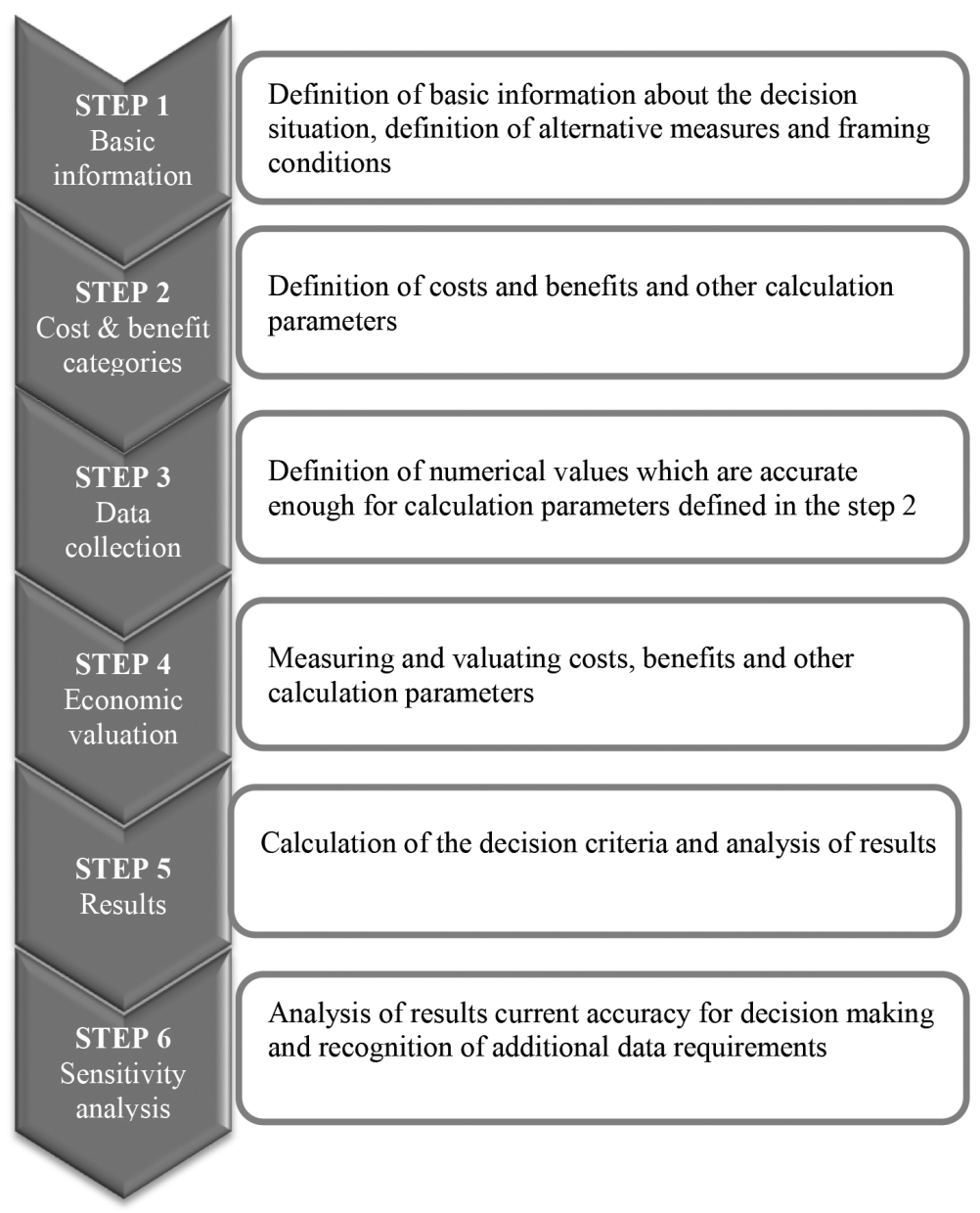

Figure 2: RESEC - process steps [23].

the meteorological simulations can give the precipitation in a particular area, and it can be used as the input for the hydrological tools, and then the other tools could establish the vulnerability, impact and economic cost of the simulated event. However, only in an ideal situation are the related methods and tools designed to fully interact with each other that can result in discrepancies between the tools. This should also be taken into account when applying the framework and validating the results in the INTACT project.

\section{CONCLUSIONS}

This paper proposes a logical and practical framework to assess the impacts of EWE on critical infrastructure and the resilience of $\mathrm{CI}$ against extreme weather. Furthermore, it contributes to the more comprehensive use of available information affecting the risk assessment, the analysis of the effectiveness of mitigation investments and the resilience of critical infrastructure. It also briefly describes a procedure, RESEC, for evaluating the measures to protect $\mathrm{CI}$ and to reduce risk in urban areas. 
During the development of the framework, we faced the challenge that the methods and tools of assessment are typically very CI- and EWE-specific. Consequently, the choice of the tool and method depends on how much resource (time, money) can be used, and on the availability and accessibility of data. As such, the common understanding of available and realisable methods is important for the further research and development.

In the next phase of the INTACT -project, the framework described in this paper will be further evaluated, tested in case studies and developed into a tool to guide a user through a workflow-like sequence of options, guidance and recommendations. The process will be built in a wiki environment that would provide a seamless user interface.

\section{ACKNOWLEDGMENTS}

The research leading to these results has received funding from the European Union Seventh Framework Programme (FP7/2007-2013) under grant agreements $n^{\circ} 606799$ (INTACT) and $\mathrm{n}^{\circ} 312013$ (HARMONISE). The information and views set out in this article are those of the author(s) and do not necessarily reflect the official opinion of the European Union. Neither the European Union institutions and bodies nor any person acting on their behalf may be held responsible for the use which may be made of the information contained therein. Reproduction is authorised provided the source is acknowledged.

\section{REFERENCES}

[1] The HARMONISE-project, A Holistic Approach to Resilience and Syste Matic Actions to Make Large Scale Urban Built Infrastructure Secure http://harmonise.eu/

[2] Luiijf, E., Nieuwenhuijs, A., Klaver, M., Eeten, M. \& Cruz, E., Empirical findings on critical infrastructure dependencies in europe. In Critical Information Infrastructure Security: Third International Workshop, CRITIS 2008, Rome, Italy, Revised Papers, Springer-Verlag, pp. 302-310, 2009.

http://dx.doi.org/10.1007/978-3-642-03552-4_28

[3] Räikkönen, M., Pilli-Sihvola, K., Kunttu, S., Yliaho, J., Jähi, M., Zuccaro, G. \& Del Cogliano, D., Assessing economic impacts of crises - a decision-support approach to long-term strategic planning. Proceedings of the IX International Conference on Risk Analysis and Hazard Mitigation, C.A. Brebbia, WIT Press (Wessex Institute of Technology), pp. 229-241. Risk Analysis 2014. New Forest, UK, 2014. http://dx.doi.org/10.2495/risk140201

[4] Nieuwenhuijs, A., \& Geerdink, T. (eds), Report on Structure and Content of the IRG, INTACT Deliverable D6.1, project co-funded by the European Commission under the 7th Framework Programme, 2015.

[5] Fingrid. Jatkunut myrsky aiheutti uusia vikoja. [Online] www.fingrid.fi/fi/ajankohtaista/ tiedotteet/Sivut\%2FJatkunut-myrsky-aiheutti-uusiavikoja.aspx

[6] Fingrid, Talvimyrskyn vaikutukset kantaverkkoon 26.-27.12.2011. [Online] www. fingrid.fi/fi/ajankohtaista/tiedotteet/Sivut\%2FTalvimyrskyn-vaikutuksetkantaverkkoon-26.-27.12.2011-\%28P\%C3\%A4ivitetty-9.1.2012\%29.aspx

[7] Mäki, K., Forssén K. \& Vidar Vangelsten, B. (eds), Factors Contributing to CI Vulnerability and Resilience, INTACT Deliverable D3.2, project co-funded by the European Commission under the 7th Framework Programme, 2015.

[8] Millet, I. \& Wedley, W.C., Modelling risk and uncertainty with the analytic hierarchy process. Journal of Multicriteria Decision Analysis, 11(2), pp. 97-107, 2002.

http://dx.doi.org/10.1002/mcda.319 
[9] ISO 31000, Risk management - Principles and Guidelines, International Organization for Standardization, 24 p., 2013.

[10] Cavasogly, H., Making sound security investment decisions. Journal of Information Privacy \& Security, 6(1), pp. 53-71, 2010. http://dx.doi.org/10.1080/15536548.2010.10855881

[11] Aven, T. \& Renn, O., Risk Management and Governance, Concepts, Guidelines and Applications, Springer Berlin Heidelberg, Vol. 16, 2010.

[12] IRGC - International risk governance council. An introduction to the IRGC Risk Governance Framework, 2012.

[13] McCord, M., Rodgers, J., Davis, P., Haran, M. \& Berchtold, C., SOTA gaps and guidance parameters for all WP's, INTACT Deliverable D1.1, project co-funded by the European Commission under the 7th Framework Programme, 2015.

[14] SE Handbook, Systems Engineering Handbook-A Guide for System life Cycle Processes and Activities, San Diego: INCOSE, 2011.

[15] ISO IEC 15288, Systems and Software Engineering - System Life Cycle Processes, (IEEE Std 15288-2008), 2 edn, 2008.

[16] ISO IEC 26702. Systems engineering - application and management of the systems engineering process, (IEEE Std 1220-2005), 1 edn, 2007.

[17] Tiusanen, R., An Approach for the Assessment of Safety Risks in Automated Mobile Workmachine Systems, Espoo, VTT. 200 p. + app. 6 p. VTT Science, 69, 2014.

[18] UNISDR. 2009 UNIDSR terminology on disaster risk reduction, Geneva, Switzerland, Nations. 30 p, 2009.

[19] Kröger, W. \& Zio, E., Vulnerable Systems, Springer, 2011.

[20] McKenzie, E., Prasad, B. \& Kaloumaira, A., Guidelines for estimating the economic impact of natural disasters in the pacific. The Australia Agency for International Development, pp. 1-38, 2005.

[21] Middelmann, M.H. (Ed), Natural Hazards. Identifying Risk Analysis Requirements in Australia. Chapter 2: Impact of Natural Disasters. Department of Industry, Tourism \& Resources Minister for Industry, Tourism \& Resources: The Hon. Ian Macfarlane, MP Parliamentary Secretary: The Hon. Bob Baldwin, MP. pp. 7-29, 2007.

[22] Räikkönen, M., Rosqvist, T., Poussa, L. \& Jähi, M., A framework for integrating economic evaluation and risk assessment to support policymakers' security-related decision. Proceedings of the 11th International Probabilistic Safety Assessment and Management Conference \& The Annual European Safety and Reliability Conference, The European Safety and Reliability Association (ESRA), PSAM11 \& ESREL 2012, Helsinki, 2012, USB memory stick, pp. 18-Tu3-2, 2012.

[23] Räikkönen, M., Kunttu, S., Murtonen, M. \& Jähi, M., Economic Evaluation of Large Scale Urban Built Infrastructure - Introducing the RESEC Method, VTT Technology 260, 37p. + app.3 p. http://www.vtt.fi/inf/pdf/technology/2016/T260.pdf, ISBN 978951-38-8421-5, VTT, Espoo, 2016. 